\title{
M-CSF, TNF $\alpha$ and RANK ligand promote osteoclast survival by signaling through mTOR/S6 kinase
}

\author{
H Glantschnig ${ }^{1}$, JE Fisher ${ }^{1}$, G Wesolowski ${ }^{1}$, GA Rodan ${ }^{1}$ \\ and AA Reszka*,1 \\ ${ }^{1}$ Bone Biology and Osteoporosis Research, Merck and Co., Inc., West Point, \\ PA, USA \\ * Corresponding author: AA Reszka, Merck Research Laboratories, WP26A- \\ 1000, West Point, PA 19486, USA. Tel: 215-652-1410; \\ Fax: 215-652-4328; E-mail: Alfred_Reszka@merck.com
}

Received 28.11.02; revised 04.4.03; accepted 05.5.03

Edited by $\mathrm{H}$ Ichijo

\begin{abstract}
Multinucleated bone-resorbing osteoclasts $(0 \mathrm{cl})$ are cells of hematopoietic origin that play a major role in osteoporosis pathophysiology. Ocl survival and activity require M-CSF and RANK ligand (RANKL). M-CSF signals to Akt, while RANKL, like TNF $\alpha$, activates NF- $\kappa$ B. We show here that although these are separate pathways in the Ocl, signaling of all three cytokines converges on mammalian target of rapamycin (mTOR) as part of their antiapoptotic action. Accordingly, rapamycin blocks M-CSF- and RANKL-dependent Ocl survival inducing apoptosis, and suppresses in vitro bone resorption proportional to the reduction in Ocl number. The cytokine signaling intermediates for mTOR/ribosomal protein S6 kinase (S6K) activation include phosphatidylinositol-3 kinase, Akt, Erks and geranylgeranylated proteins. Inhibitors of these intermediates suppress cytokine activation of $\mathrm{S} 6 \mathrm{~K}$ and induce $\mathrm{Ocl}$ apoptosis. $\mathrm{mTOR}$ regulates protein translation acting via $\mathrm{S} 6 \mathrm{~K}, 4 \mathrm{E}-\mathrm{BP} 1$ and $\mathrm{S} 6$. We find that inhibition of translation by other mechanisms also induces $\mathrm{Ocl}$ apoptosis, demonstrating that Ocl survival is highly sensitive to continuous de novo protein synthesis. This study thus identifies $\mathrm{mTOR} / \mathrm{S} 6 \mathrm{~K}$ as an essential signaling pathway engaged in the stimulation of cell survival in osteoclasts.

Cell Death and Differentiation (2003) 10, 1165-1177. doi:10.1038/ sj.cdd. 4401285
\end{abstract}

Keywords: apoptosis; survival; S6 kinase; rapamycin; osteoclast

Abbreviations: Ocl, osteoclast; S6, ribosomal protein S6; S6K, ribosomal protein $\mathrm{S} 6$ kinase; mTOR, mammalian target of rapamycin; $\mathrm{PI} 3 \mathrm{~K}$, phosphatidylinositol-3 kinase

\section{Introduction}

Osteoclasts (Ocls) are terminally differentiated multinucleated cells that resorb bone. High Ocl activity leads to bone loss associated with postmenopausal osteoporosis and Paget's disease, among others. Ocl differentiation, activity and survival is regulated by the concerted action of cytokines and growth factors, synthesized by osteoblasts, stromal cells, or other cells of hematopoietic origin. ${ }^{1-3}$

Among the factors essential for Ocl generation, function and survival are $\mathrm{M}^{-\mathrm{CSF}^{4-6}}$ and the ligand for the receptor activator of NF- $\kappa$ B RANK ligand (RANKL, also named ODF, OPGL or TRANCE), a member of the TNF family. ${ }^{7-9}$ Although less clear, a role for TNF $\alpha$ in Ocl differentiation and activation has also been shown. ${ }^{10-12}$ The fine -tuning between bone resorption by Ocl and bone formation by osteoblasts is critical for the preservation of bone mass. Since Ocl lifespan could influence overall resorptive activity, regulation of Ocl apoptosis was proposed to be one of the mechanisms for controlling bone resorption. ${ }^{13,14}$

Apoptosis is a genetically programmed, morphologically distinct form of cell death that can be triggered by a variety of physiological and pathological stimuli. Regulation of Ocl survival is coordinated in part by proteins synthesized and presented by cells of the osteoblast lineage, including M-CSF and RANKL. Ocl differentiation in vitro depends on exogenous $\mathrm{M}$-CSF, ${ }^{15}$ and M-CSF removal from purified Ocl cultures results in caspase and MST1 kinase activation, leading to apoptosis. ${ }^{16}$ Soluble RANKL (sRANKL) and TNF $\alpha$ have also been shown to support Ocl survival in addition to their effect on differentiation. ${ }^{17,18}$ However, a common mechanism, if any, by which these prosurvival cytokines exert antiapoptotic effects in Ocl remains unknown.

Signaling by M-CSF has been shown to activate phosphoinositide 3-kinase (PI3K) and antiapoptotic Akt (also known as PKB) kinase in Ocl. ${ }^{19}$ Akt activity is necessary and in some cases sufficient for cell survival and has been shown to target the apoptotic machinery by phosphorylating downstream molecules like BAD, caspase-9, glycogen-synthase kinase and forkhead family members. ${ }^{20,21}$ RANKL and TNF $\alpha$ act primarily via NF- $\kappa$ B activation leading to the transcription and de novo synthesis of antiapoptotic proteins. ${ }^{22}$ However, some studies suggest that RANKL and TNF $\alpha$ can stimulate the Akt pathway involving c-src kinase. ${ }^{18,23,24}$ Additionally, although controversial, Akt activity has been suggested to be required for NF- $\kappa$ B induction by TNF. ${ }^{25,26}$

The mammalian target of rapamycin (mTOR, also known as FRAP or RAFT) is a serine/threonine kinase that plays a central role in the control of translation. mTOR might act as a master switch of cellular catabolism and anabolism. ${ }^{27}$ Both mTOR and p70 ribosomal protein S6 kinase (S6K) are regulated via PI3K effectors, including Akt and phosphoinositide-dependent kinase 1 (PDK1). ${ }^{28-31}$ Akt relieves mTOR from tuberous sclerosis complex (TSC1/2)-mediated suppression by phosphorylation of TSC2. Both PDK1 and mTOR have been shown to phosphorylate S6K at Thr389 and release the kinase from autoinhibition. ${ }^{31,32}$ The penultimate activation step at this site, however, seems to be provided by NEK6, a newly identified S6K kinase. ${ }^{33}$ Only after the release of autoinhibition does PDK1 efficiently phosphorylate and 
activate S6K within the activation loop. The mTOR/S6K pathway has been shown to regulate translation via phosphorylation of 4E-BP1 and ribosomal protein S6 (S6); ${ }^{34}$ and antiapoptotic signaling by phosphorylation of $\mathrm{BAD}^{35}$ (reviewed in Castedo et al. $^{27}$ ).

Guided by the observation that inhibitors of translation cause rapid apoptosis in Ocl, we investigated prosurvival signaling through the translational control pathway mTOR/ S6K in these cells. We found an antiapoptotic pathway involving $\mathrm{mTOR} / \mathrm{S} 6 \mathrm{~K}$ that is commonly engaged by M-CSF, TNF $\alpha$ and RANKL. Inhibition of mTOR results in Ocl apoptosis and suppression of bone resorption in vitro, suggesting that mTOR control of protein translation can be rate limiting in the control of the Ocl lifespan.

\section{Results}

\section{Osteoclastogenic cytokines suppress both basal- and alendronate-induced apoptosis}

Apoptosis was measured in purified Ocls in the absence or presence of alendronate ( $A L N)$, a bisphosphonate widely used in the treatment of osteoporosis. ALN-induced Ocl apoptosis (Figure 1a) is associated with the formation of apoptotic bodies (arrows) that form a ring-like array and/or retraction of the cell, accompanied by formation of pyknotic nuclei (inset), as we have previously described. ${ }^{16}$ Apoptosis in $\mathrm{Ocl}$ is accompanied by caspase activation of proapoptotic MST1 kinase. ${ }^{16}$ (Figure 1b-d). After caspase cleavage, $36 \mathrm{kDa}$ MST1 kinase further increases caspase activity and promotes apoptosis. ${ }^{36-38}$ The activity of caspase-cleaved MST1 can serve as a quantitative biochemical marker for apoptosis in the Ocl, and relative induction (versus control) is indicated below each in-gel kinase assay lane in Figure 1.

The mechanism of ALN-induced apoptosis is by suppression of protein geranylgeranylation, ${ }^{16}$ thus coincubation with geranylgeraniol (GGOH; Figure $1 \mathrm{a}$ and b) blocked ALN effects. Consistent with previous reports, ${ }^{16,39,40}$ inhibition of type I geranylgeranyltransferase by a highly selective inhibitor geranylgeranyltransferase-1 inhibitor-2 (GGTI- $2^{41}$ ) mimicked ALN effects on Ocl apoptosis (Figure 1b). GGTI-2and $A L N$-induced morphological features of apoptosis and caspase-cleaved $36 \mathrm{kDa}$ MST1 activities (3.6- and four-fold, respectively; Figure 1b) were essentially indistinguishable. Apoptosis induced by GGTI-2 and ALN could be suppressed by addition of $\mathrm{GGOH}$, as seen with $36 \mathrm{kDa}$ MST1 activity that was reduced to baseline levels (Figure 1b). This is consistent with the observation that GGTI2 inhibits geranylgeranyltransferase in a geranylgeranyldiphosphate competitive manner (Hans Huber, personal communication).

Ocls require cytokines, especially M-CSF, for their survival in vivo and in vitro. In addition to M-CSF, RANKL is required for Ocl differentiation and bone resorption, and RANKL, TNF $\alpha$ and IL- $1 \alpha$ can help to suppress apoptosis in these cells. We therefore examined if these cytokines have additive effects with a minimal level of M-CSF $(5 \mathrm{ng} / \mathrm{ml})$ on suppression of Ocl apoptosis induced by ALN or GGTI-2. Both spontaneous and ALN-induced apoptosis could be suppressed to baseline levels or below by additionally treating with sRANKL, TNF $\alpha$ or IL- $1 \alpha$, as quantified by the activity of caspase-cleaved MST1 kinase (Figure 1b). Antiapoptotic effects extended to the prevention of morphological disruption (Figure 1a). Similar effects were seen in the suppression of GGTI-2-induced apoptosis (Figure 1b), with MST1 caspase cleavage suppressed to below baseline. Largest effects on caspasecleaved $36 \mathrm{kDa}$ MST1 kinase activity were observed when TNF $\alpha, I L-1 \alpha$ and M-CSF were combined (Figure $1 \mathrm{~b}$ ), and kinase activities in control, ALN- or GGTI-2-treated Ocls were reduced to $70 \%$ below baseline. This was similar to the effect of GGOH on ALN-induced apoptosis, which resulted in a 10fold reduction in $36 \mathrm{kDa}$ MST1 kinase activity (Figure 1b, lane 12). The effects of RANKL on ALN-induced apoptosis were dose dependent (Figure 1c), resulting in up to an $80 \%$ reduction in activity of the $36 \mathrm{kDa}$ MST1 kinase. Similar dose dependencies were obtained with TNF $\alpha$ or IL-1 $\alpha$ (data not shown).

Under control conditions and in the absence of M-CSF (i.e. no exogenous apoptotic or antiapoptotic agent) Ocl exhibited spontaneous apoptosis as measured by detection of $36 \mathrm{kDa}$ MST1 kinase (Figure 1d, lane 1), along with actin disruption, nuclear condensation, membrane blebbing and cellular lysis (data not shown). As expected, M-CSF dose-dependently suppressed spontaneous apoptosis and essentially completely blocked MST1 cleavage by up to five-fold when used at $30 \mathrm{ng} / \mathrm{ml}$ or above (Figure 1d, lanes 2-6). Interestingly, ALN-induced apoptosis was also dose-dependently suppressed by M-CSF (Figure 1d, lanes 7-12), whereby $36 \mathrm{kDa}$ MST1 kinase activity was reduced up to 12-fold $(100 \mathrm{ng} / \mathrm{ml} \mathrm{M-CSF})$ to levels seen in the absence of ALN (lanes 5 and 6).

Thus, M-CSF along with TNF $\alpha$, sRANKL, and IL- $1 \alpha$, which act via different signal transduction pathways, seem to have complementary and additive effects on suppression of $\mathrm{Ocl}$ apoptosis caused by inhibition of geranylgeranylation. Timecourse experiments indicated that each of these cytokines delayed ALN- or GGTI-2-induced apoptosis by approximately 10-12 h (data not shown). These observations suggested the possibility of a common pathway in the prosurvival signaling of these agents.

\section{Nonoverlapping Akt and NF- $\kappa$ B pathways induced by M-CSF and TNF $\alpha /$ sRANKL}

We first examined in Ocl, potential overlap in the known signal transduction pathways of M-CSF, TNF $\alpha$ and sRANKL, starting with $\mathrm{NF}-\kappa \mathrm{B}$ and Akt. Using phospho-specific antibodies, we found that M-CSF rapidly induced activation of Akt by phosphorylating residues Thr308 and Ser473 (Figure 2a). M-CSF had no detectable effects on the NF- $\kappa$ B pathway, evaluated by phosphorylation and degradation of $\mathrm{I} \kappa \mathrm{B} \alpha$ (Figure $2 \mathrm{a}$ ) or binding of free NF- $\kappa \mathrm{B}$ (i.e. not complexed with $1 \kappa \mathrm{B}$ ) to DNA (Figure $2 \mathrm{~b}$ ).

TNF $\alpha$ and SRANKL induced very limited activation of Akt at Thr308 and Ser473, when compared to M-CSF. However, both cytokines induced phosphorylation of $\mathrm{I}_{\kappa} \mathrm{B} \alpha(\operatorname{Ser} 32 / 36)$ at $5 \mathrm{~min}$. For TNF $\alpha$, its more potent induction of $\mathrm{I}_{\kappa} \mathrm{B} \alpha$ phosphorylation was followed by partial proteosomal degradation and 
a
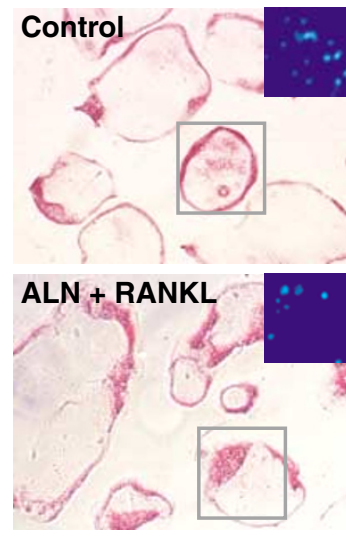

b
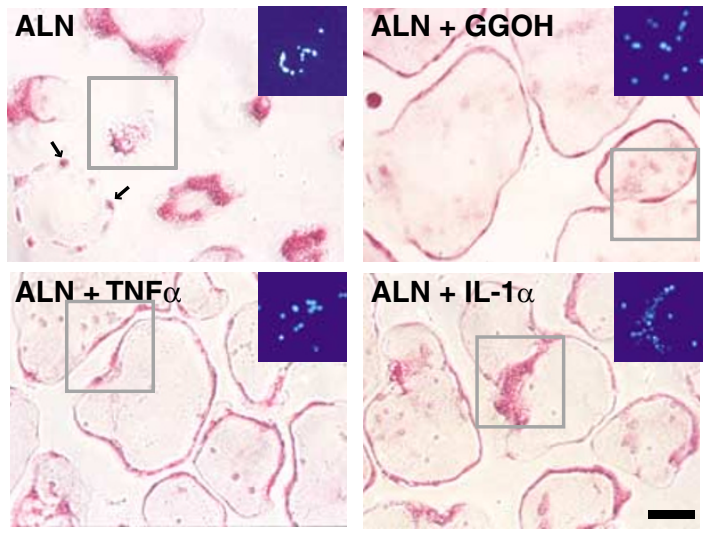

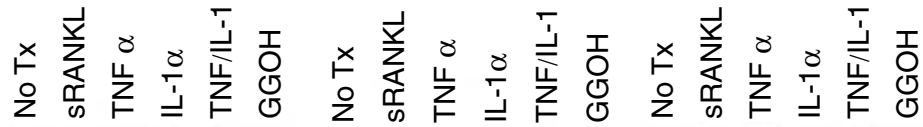
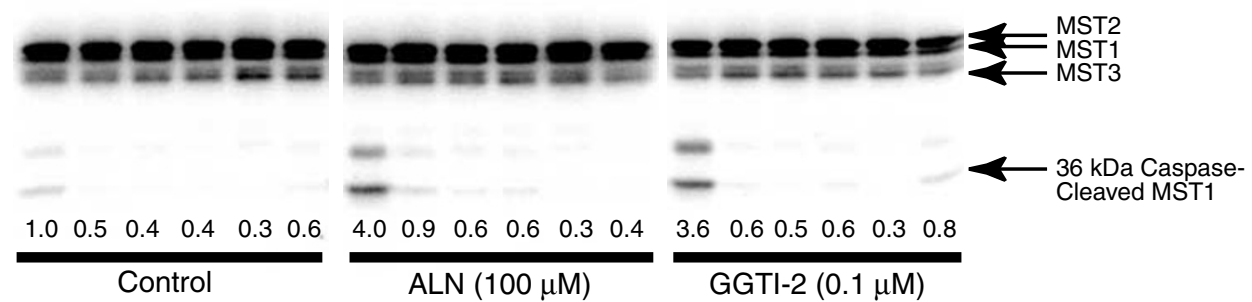

C

$\begin{array}{llllllllllll}0 & 5 & 10 & 30 & 60 & 200 & 0 & 5 & 10 & 30 & 60 & 200\end{array}(\mathrm{ng} / \mathrm{mL}$ sRANKL) + M-CSF

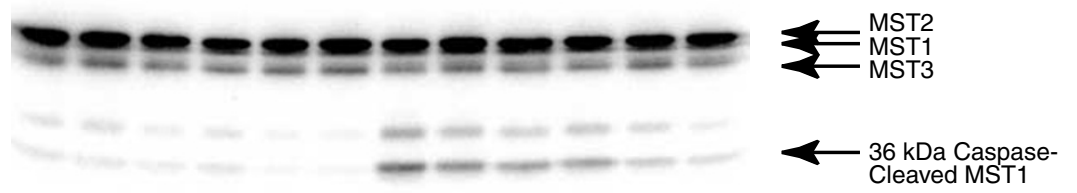

$\begin{array}{llllllllllll}1.0 & 1.2 & 0.9 & 1.1 & 0.7 & 0.8 & 5.7 & 4.1 & 3.3 & 3.1 & 1.7 & 1.2\end{array}$

Control

ALN $(50 \mu \mathrm{M})$

d

$\begin{array}{lllllllllllll}0 & 1 & 3 & 10 & 30 & 100 & 0 & 1 & 3 & 10 & 30 & 100 & \text { (ng/mL M-CSF) }\end{array}$

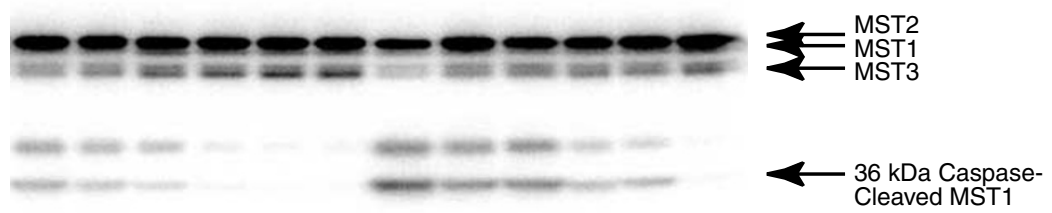

$\begin{array}{llllllllllll}1.0 & 0.7 & 0.5 & 0.3 & 0.2 & 0.3 & 2.5 & 1.6 & 1.7 & 0.9 & 0.8 & 0.2\end{array}$

Control

ALN $(50 \mu \mathrm{M})$

Figure 1 Inhibition of spontaneous and ALN-, or GGTI-2 induced Ocl apoptosis by survival cytokines M-CSF, TNF $\alpha$, RANKL and IL-1 $\alpha$. (a) Morphological effects of cytokines on ALN induction of apoptosis. In all groups, $5 \mathrm{ng} / \mathrm{ml} \mathrm{M-CSF}$ was included to provide minimal Ocl survival. Ocl were untreated (Control) or further treated with ALN $(50 \mu \mathrm{M})$ alone or with added GGOH $(10 \mu \mathrm{M})$, sRANKL $(100 \mathrm{ng} / \mathrm{ml})$, TNF $\alpha(50 \mathrm{ng} / \mathrm{ml}), \mathrm{LL}-1 \alpha(50 \mathrm{ng} / \mathrm{ml})$ or TNF $\alpha+\mathrm{IL}-1 \alpha$. After $16 \mathrm{~h}$, Ocl were stained for TRAP (red) and with Hoechst 33342 (blue). (b) In comparison to $5 \mathrm{ng} / \mathrm{ml} \mathrm{M-CSF}$ alone (no Tx), effects on Ocl apoptosis of: sRANKL (100 ng/ml), TNF $\alpha(50 \mathrm{ng} / \mathrm{ml})$, IL-1 $\alpha$ ( $50 \mathrm{ng} / \mathrm{ml}$ ), TNF $\alpha+\mathrm{IL}-1 \alpha$, or GGOH $(10 \mu \mathrm{M})$, each combined with $5 \mathrm{ng} / \mathrm{ml} \mathrm{M-CSF}$. Spontaneous apoptosis (Control) or that induced with ALN (100 $\mu \mathrm{M}$; b and c) or GGTI-2 (0.1 $\mu \mathrm{M})$ for $16 \mathrm{~h}$ was assessed. Ocl apoptosis was assessed by measuring the activity of the $36 \mathrm{kDa}$ MST1 kinase caspase cleavage product by in-gel kinase assays as described in Materials and Methods. Fold activation of $36 \mathrm{kDa}$ MST1 kinase (versus control) is noted beneath each phosphorimage. Arrows indicate full-length MST1 kinase and the $36 \mathrm{kDa}$ cleavage product, as well as MST2 and MST3 protein kinases. (c) Effects of increasing concentrations of sRANKL on inhibition of spontaneous (Control) and ALN $(50 \mu \mathrm{M})$ induced Ocl apoptosis in the presence of $5 \mathrm{ng} / \mathrm{ml} \mathrm{M-CSF}$ (in-gel kinase assay). (d) Effects of increasing concentrations of M-CSF on inhibition of spontaneous (Control) and ALN (50 $\mu \mathrm{M})$-induced Ocl apoptosis (in-gel kinase assay) 

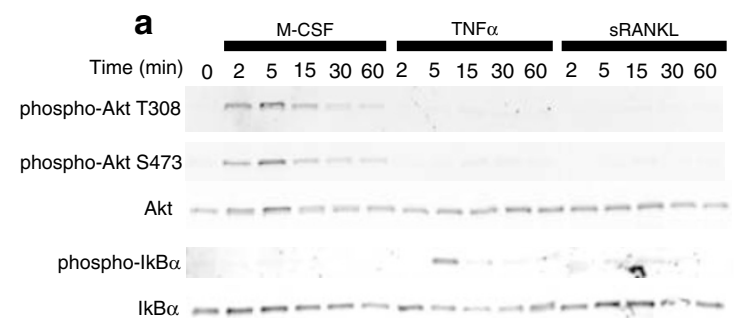

b

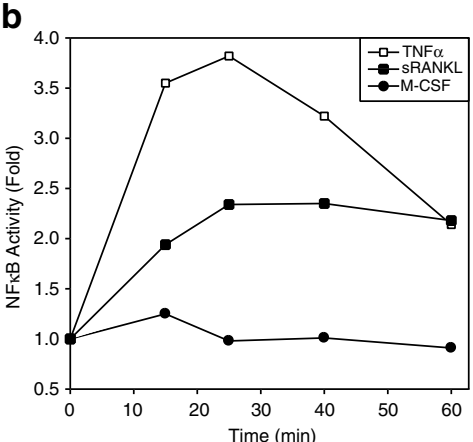

Figure 2 Selective effects of M-CSF, TNF $\alpha$ and sRANKL on stimulation of the Akt and NF $\kappa$ B pathways. (a) Purified Ocl were treated with M-CSF, TNF $\alpha$ and sRANKL for 0-60 min, as indicated. Cell lysates were immunoblotted with phospho-specific antibodies for Akt (Thr308 or Ser473) and $l_{\kappa} \mathrm{B} \alpha(\mathrm{Ser} 32 / 36)$ as described in Materials and Methods. (b) NF- $\kappa$ B activation was measured, as described in Materials and Methods, after treatment with TNF $\alpha$ (open squares), sRANKL (closed squares) or M-CSF (closed circles) for 15-60 min, as indicated. For NF- $\kappa \mathrm{B}$ assays in (b), effective measurement required the pooling of cell lysates derived from multiple identically treated wells. A total of three pooledsampling experiments were performed, with similar results

recovery of $I_{\kappa} B \alpha$ protein level. For SRANKL, we repeatedly found a modest level of $I_{\kappa} B \alpha$ phosphorylation that lasted up to $15 \mathrm{~min}$, although little degradation of $\mathrm{I}_{\kappa} \mathrm{B} \alpha$ was observed. We therefore examined NF- $\kappa$ B activation in separate time-course experiments (Figure $2 \mathrm{~b}$ ). Despite slightly differing in $\mathrm{I} \kappa \mathrm{B} \alpha$ phosphorylation and degradation, both TNF $\alpha$ and SRANKL induction of NF- $\kappa \mathrm{B}$ activation peaked at $25 \mathrm{~min}$. Consistent with the more potent effect on $\mid \kappa \mathrm{B} \alpha$, the magnitude of induction by TNF $\alpha$ was greater than with sRANKL. However, this difference was transient and both effects were comparable at $60 \mathrm{~min}$. As noted above, M-CSF failed to stimulate NF$\kappa \mathrm{B}$ appreciably over this time course. Thus, M-CSF and TNF $\alpha /$ sRANKL survival cytokines seem to induce different essentially nonoverlapping intracellular signaling pathways in Ocl.

\section{Ocl require continuous protein translation for survival}

Identification of mTOR/S6K as critical for Ocl survival stemmed from analyses of $\mathrm{TNF} \alpha$ proapoptotic (caspase activation) versus antiapoptotic (NF- $\kappa \mathrm{B}-$ mediated) signaling. $\mathrm{TNF} \alpha$ induces apoptosis when cells are treated with a protein synthesis inhibitor such as cycloheximide (CHX) or when NF$\kappa \mathrm{B}$ signaling is blocked. ${ }^{42,43}$ Unexpectedly, we found that treatment of Ocl with translational inhibitors alone resulted in pronounced, rapid, apparently synchronous induction of Ocl apoptosis (Figures 3 and 4). In these experiments, translation was inhibited by three different mechanisms: (1) inhibition of ribosomal translocase activity with $\mathrm{CHX}$; (2) premature termination of the growing polypeptide chain by puromycin, a tRNA analog; and (3) blocking ribosome movement along mRNA with emetine. For comparison, the RNA-polymerase inhibitor actinomycin D was used to inhibit transcription. Within $2 \mathrm{~h}$ of inhibiting translation with cycloheximide (Figure $3 b, b^{\prime}$ ), emetine (Figure $3 c, c^{\prime}$ ) and puromycin (data not shown; indistinguishable from $\mathrm{CHX}$ ), we observed distinct changes in Ocl morphology, which were consistent with the induction of apoptosis. This included cell retraction, loss of actin ring structure, membrane blebbing and nuclear condensation. After $4 \mathrm{~h}$, all tartrate-resistant acid phosphatases (TRAP)-positive cells were apoptotic. Actinomycin D treatment (Figure 3d, $d^{\prime}$ ) showed no morphological effects within this time frame. For all treatments, there was no evidence of cell survival after overnight exposure ( $16 \mathrm{~h}$ ).

Apoptotic events induced by translation inhibitors were further characterized by measuring activities of initiator (caspase-9) and effector caspases (i.e. caspase-3) (Figure $4 \mathrm{a}$ ) and the activity of the caspase cleavage product, $36 \mathrm{kDa}$ MST1 (Figure 4b). With translation inhibitors, caspase- 9 activity increased six- to eight-fold and caspase- 3 by 20-30-fold after $1 \mathrm{~h}$. Consistent with a highly synchronous induction of apoptosis, caspase- 9 activity increased by 50-125-fold and caspase-3 by 100-200-fold, measured after 2-3h. With a slower induction of apoptosis, the transcriptional inhibitor actinomycin D did not activate these caspases until $3 \mathrm{~h}$, at which time caspase- 9 and -3 were activated by $22-$ and 47 -fold, respectively. This was consistent with the morphological appearance of apoptosis in actinomycin D-treated cultures at about $4 \mathrm{~h}$ (data not shown).

$\mathrm{CHX}$, puromycin or emetine treatment also stimulated cleavage and activation of MST1 kinase by 14-35-fold, depending on the treatment (Figure 4b). At the same time point $(2.75 \mathrm{~h})$, control Ocls showed very little spontaneous apoptosis and actinomycin D had minimal effects on MST1 cleavage (1.2-fold). The actinomycin response was consistent with delayed caspase activation, as noted above. These data indicate that Ocl survival requires continuous de novo protein synthesis and a lack thereof results in rapid initiation and progression of the apoptotic program. We therefore investigated a possible role for a signaling pathway controlling translation in cytokine promotion of Ocl survival.

\section{Ocl antiapoptotic cytokines signal through the mTOR/S6K pathway}

Based on the observation that translation plays a central role in Ocl survival, we examined the mTOR/S6K translational control pathway, as a possible common integrator for survival signaling in Ocl. Indeed, M-CSF, TNF $\alpha$ and SRANKL all stimulated phosphorylation of S6K1 (p70) and S6K2 (p54) isoforms in Ocl (Figure 5a). Antibody recognition of an $85 \mathrm{kDa}$ band, possibly p85 S6K1 and/or PKC, was unchanged. Consistent with an increase in mTOR activity, the cytokines also induced phosphorylation of its direct substrate, 4E-BP1 at Ser65. 

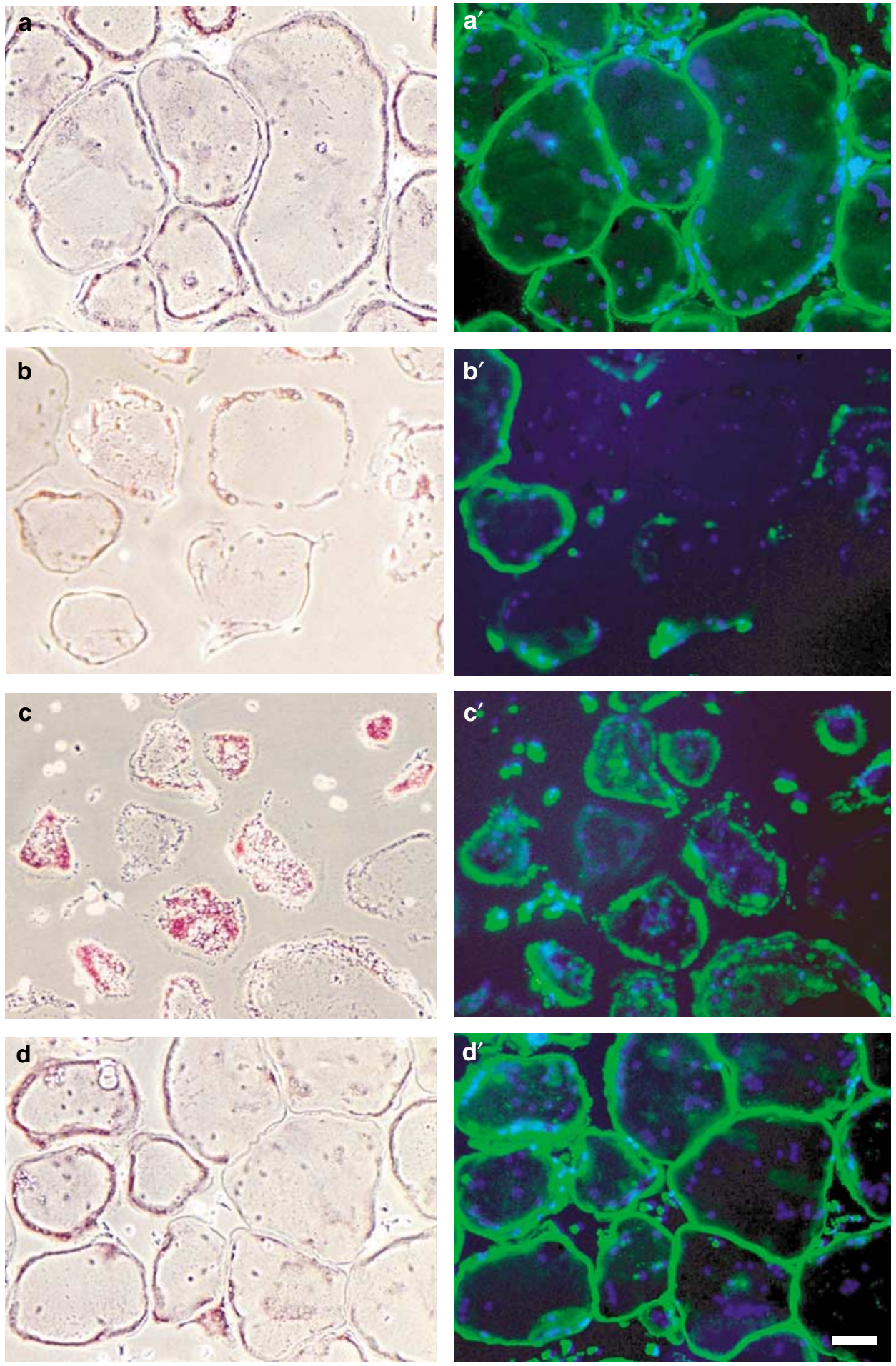

Figure 3 Inhibition of translation rapidly induces Ocl apoptosis. Ocl were prepared as in Figure 1 and left untreated $\left(\mathbf{a}, \mathbf{a}^{\prime}\right)$, or were treated with $\mathrm{CHX}\left(\mathbf{b}, \mathbf{b}^{\prime}\right)$, emetine $(\mathbf{c}$, $\left.\mathbf{c}^{\prime}\right)$, actinomycin D $\left(\mathbf{d}, \mathbf{d}^{\prime}\right)$ for $2.75 \mathrm{~h}$. Effects of puromycin were indistinguishable from those of CHX (data not shown). Cells were fixed and stained for TRAP activity (ad). Nuclear integrity was assessed using Hoechst No. 33342 (Blue), and FITC-phalloidin (Green) was used to visualize the actin cytoskeleton (a'- $\mathbf{d}^{\prime}$ ). Bar $100 \mu \mathrm{M}$

Consistent with the activation of S6K by these cytokines, phosphorylation of the S6K substrate, S6 (Ser235/6), was also observed. By this measure, S6K activity increased several fold after $15 \mathrm{~min}$ exposure to M-CSF, TNF $\alpha$ or sRANKL and remained elevated for up to $60 \mathrm{~min}$ (Figure $5 \mathrm{~b}$ ).
For M-CSF, peak phosphorylation was observed at 15 and 30 min, while with TNF $\alpha$ and SRANKL, peak phosphorylation was observed at 30 and $60 \mathrm{~min}$. Parallel measurements of these cell lysates showed that Akt phosphorylation was rapidly and transiently induced only by M-CSF. TNF $\alpha$ and 
sRANKL similarly induced more rapid and transient effects on the phosphorylation of $\mathrm{I} \kappa \mathrm{B} \alpha$ (Figure 2a). Thus, the S6 phosphorylation seen at $15-30 \mathrm{~min}$ appeared relatively delayed versus. Akt and $\mathrm{I}_{\kappa} \mathrm{B} \alpha$ responses. As expected, the mTOR inhibitor, rapamycin, inhibited all stimulatory effects of M-CSF, TNF $\alpha$ and SRANKL on S6K (at Thr389), S6 (Ser 235/ 6) and 4E-BP1 (Ser 65) phosphorylation (Figure 5a, c and d). No effect on p85 phosphorylation was observed. Based on the rapamycin suppression of S6K and S6 phosphorylation, stimulation of S6K in this system by M-CSF, TNF $\alpha$ and sRANKL requires the catalytic activity of $\mathrm{mTOR}$. These findings indicate that mTOR is an essential component of the signaling pathways activated by these cytokines.

We also examined the effects of inhibiting PI3K (with LY294002), Akt (with Akt inhibitor) or MEK1/2 (with PD98054) on S6 phosphorylation. Activity of all three kinases is required for Ocl survival. ${ }^{18}$ Inhibition of PI3K, mTOR or Akt resulted in complete inhibition of S6 ribosomal protein Ser235/6 phosphorylation in response to either cytokine (Figure $5 \mathrm{c}$ ). Inhibition of MEK1/2 resulted in only partial reduction of S6 phosphorylation (Figure $5 \mathrm{c}$ and d). For inhibition of PI3K, we used LY294002 at a concentration of $5 \mu \mathrm{M}$, which is approximately three-fold above its $\mathrm{IC}_{50}$ for $\mathrm{PI} 3 \mathrm{~K}$ and equal to its reported $\mathrm{IC}_{50}$ for $\mathrm{mTOR}$ autokinase activity in vitro. ${ }^{44}$ Suppression of cytokine-induced S6 phosphorylation by LY294002 was complete (Figure 5c), suggesting that PI3K inhibition played a prominent role in the effect.

Downstream of PI3K, Akt acts to modulate mTOR via its effects on the TSC1/2 complex. Direct inhibition of Akt resulted in a complete loss of S6 ribosomal protein Ser235/6 phosphorylation in response to each cytokine (Figure $5 \mathrm{c}$ ). This inhibitor did not interfere with phosphorylation of Akt itself (Figure $5 \mathrm{~d}$ ). The concentration of Akt inhibitor used (10 $\mu \mathrm{M})$ was two-fold above its $\mathrm{IC}_{50}$ for suppression of Akt and eightfold below its $\mathrm{IC}_{50}$ for $\mathrm{PI} \mathrm{KK},{ }^{45}$ suggesting that this response was relatively Akt specific.

pp60 ${ }^{\mathrm{c}-\mathrm{src}}$ activity may also play a role in this part of the pathway, since it is required for signaling from PI3K to S6K and from RANKL to Akt. ${ }^{23,46}$ Consistent with these reports the src family kinase inhibitor PP1 $(10 \mu \mathrm{M})$ completely suppressed cytokine-induced activation of S6K and phosphorylation of S6 (data not shown). Therefore, in addition to mTOR, activities of PI3K, Akt and pp60 ${ }^{\text {c-src }}$ seem necessary for the downstream effects of M-CSF, TNF $\alpha$ and RANKL on S6 phosphorylation in Ocl.

Geranylgeranylated proteins, specifically Cdc42 and Rac1 GTPases, have also been implicated in S6K activation. ${ }^{47}$ Since M-CSF, sRANKL or TNF $\alpha$ delay apoptosis induced by GGTI-2 and ALN via inhibition of geranylgeranylation (see above), we investigated the effects of GGTI-2 on the

Figure 4 Translational inhibition induces caspase activation and cleavage of MST1 kinase in Ocl. Purified Ocl were left untreated (Control, closed squares) or treated with emetine (Emt, open triangles), Chx (open squares), puromycin (Puro, closed triangles) or actinomycin D (ActD, closed inverted triangles). (a) Caspase-3 activity (upper panel) and caspase-9 activity (lower panel) in pooled Ocl cell lysates were quantified after $1-3 \mathrm{~h}$ of treatment, as in Materials and Methods. A total of three pooled-sampling experiments were performed with similar results. (b) After $2.75 \mathrm{~h}$ of Ocl treatment with translational or transcriptional inhibitors, MST1 kinase activities (arrowhead) in lysates were measured by in-gel kinase assay (as in Figure 1). One representative of three independent assays is shown
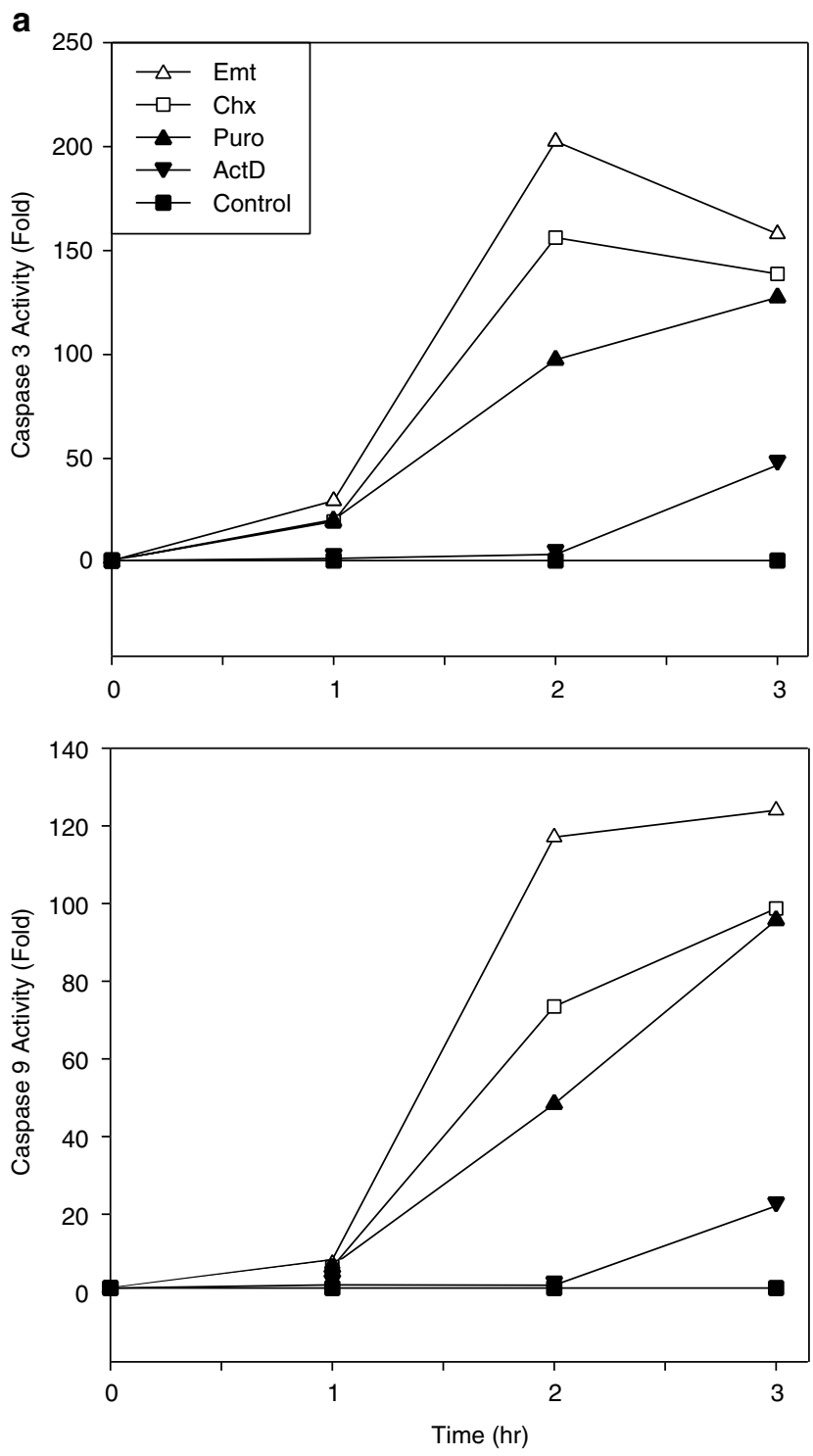

b

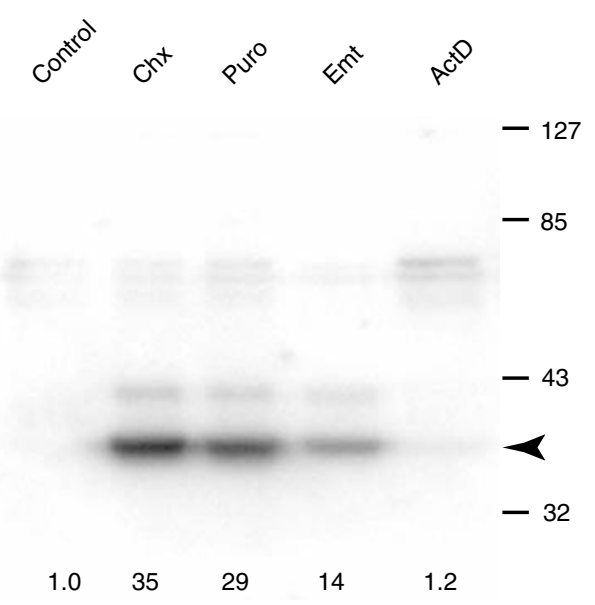




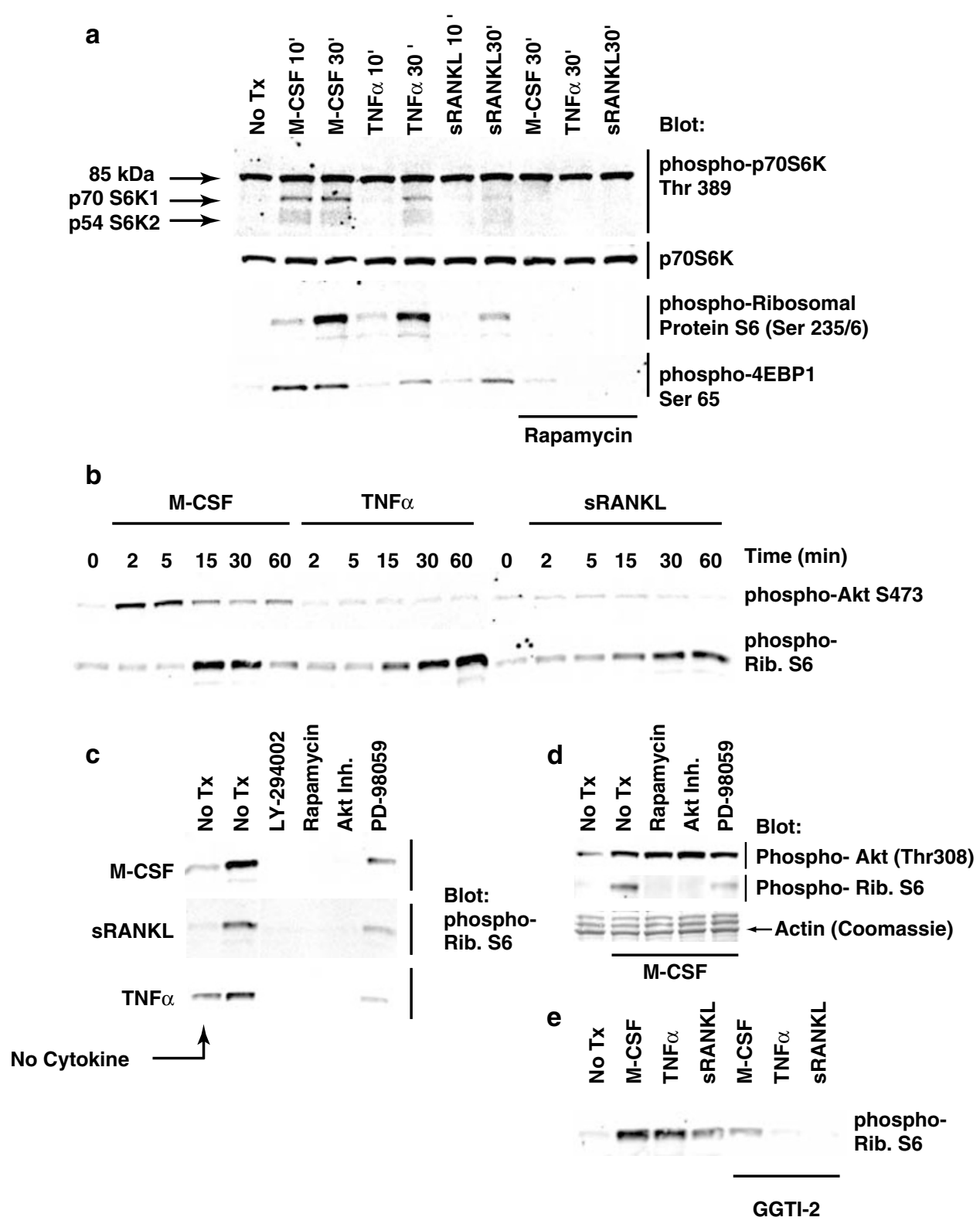

Figure 5 Induction of mTOR and S6K by M-CSF, TNF $\alpha$ and SRANKL in Ocl. (a) Purified Ocl were treated with M-CSF, TNF $\alpha$ or sRANKL for 10 or 30 min and cell lysates were prepared and probed by immunoblotting with phospho-specific antibodies as indicated. Rapamycin (100 nM) was added 30 min prior to initiation of cytokine treatments. (b) Time course for induction of S6K activity in Ocl by cytokine was assessed using phospho-specific antibodies to S6 (phospho-Ser 235/6) and Akt (phospho-Ser 473). (c) S6 phosphorylation in response to M-CSF, sRANKL and TNF $\alpha$ at 30 min was assessed as in (b) in the absence (no Tx) or presence of inhibitors of: PI3K (LY-294002; $5 \mu \mathrm{M}$ ), mTOR (Rapamycin; $100 \mathrm{nM}$ ), Akt (Akt Inh.; $10 \mu \mathrm{M}$ ) and MEK1/2 (PD-98059; $20 \mu \mathrm{M}$ ) or (e) GGTI-2 (2 $\mu \mathrm{M})$. (d) M-CSF (30 min) induction of Akt versus $\mathbf{S} 6$ phosphorylation in the presence or absence of rapamycin, Akt inhibitor or PD-98059. Inhibitors were added 30 min before cytokine treatments were started. One representative of three- to four independent assays is shown

phosphorylation of S6 ribosomal protein (Figure 5e). Pretreatment of purified Ocl with GGTI-2 for $16 \mathrm{~h}$ reduced cytokine induced $\mathrm{S} 6$ ribosomal protein phosphorylation by $60-90 \%$, depending on the cytokine tested. This suggests a possible role for geranylgeranylation in the regulation of the S6K pathway, likely through the established regulatory GTPases. ${ }^{47} \mathrm{GGTI}-2$ and ALN had no consistent or substantial effect on signaling to Akt or NF- $\kappa$ B by any of the tested cytokines, as noted above. This suggests that the geranylgeranylation requirement is relatively specific for the mTOR/S6 kinase pathway downstream of M-CSF, RANKL and TNF $\alpha$.
Overall, the suppressive effects of the signal transduction inhibitors on S6K were consistent for all three cytokines tested (M-CSF, TNF $\alpha$ and $S R A N K L$ ), indicating that signaling by these prosurvival factors in Ocl intersects prior to activation of S6K and phosphorylation of S6.

\section{mTOR/S6K signaling is required for Ocl survival and function}

Next, we investigated a possible role for mTOR activity in Ocl survival using the mTOR inhibitor, rapamycin. Rapamycin 

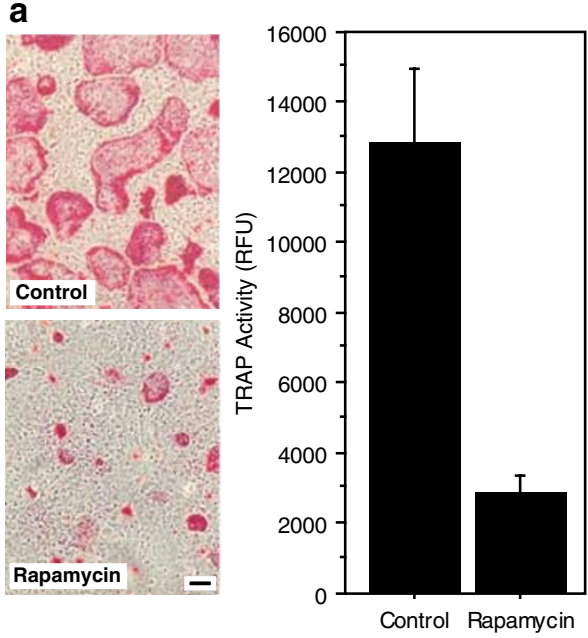

C

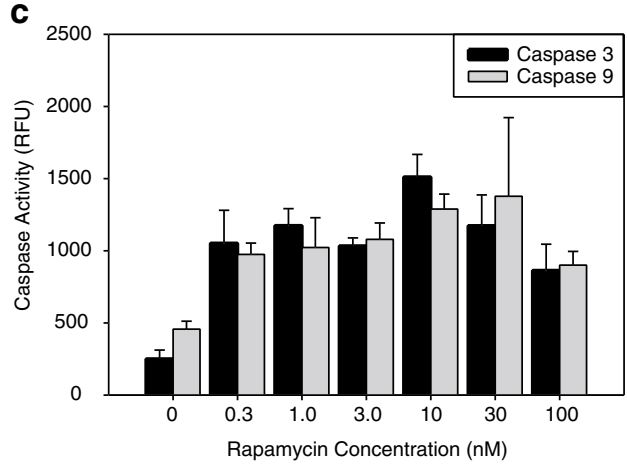

b
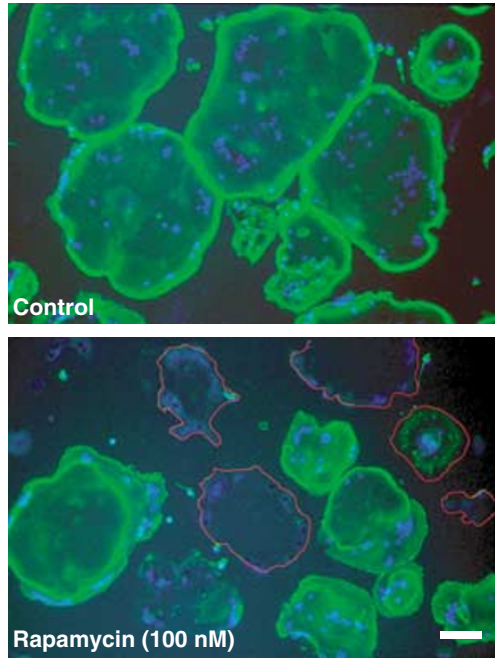

d

$\begin{array}{lllll}0 & 3 & 10 & 30 & 100\end{array}$ (nM Rapamycin)

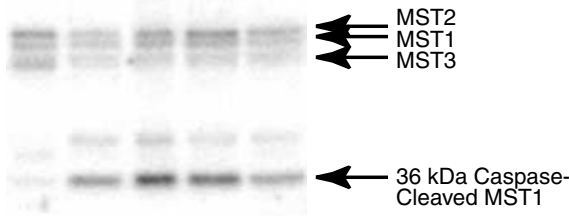

$\begin{array}{lllll}1.0 & 3.9 & 5.0 & 4.9 & 3.7\end{array}$

Figure 6 Rapamycin inhibition of mTOR induces Ocl apoptosis. (a) Osteoclastogenesis was assessed in the absence or presence of rapamycin (30 nM, days 2-7). TRAP staining (left panels) of mouse bone marrow/MB1.8 cell coculture (day 7) and quantification of TRAP activity (right panel) by a fluorescent assay as described in Materials and Methods. Values are mean \pm S.D. $(n=8)$; bar is $100 \mu \mathrm{M}$. (b) Purified Ocl were treated with rapamycin (100 $\mathrm{nM})$ for $20 \mathrm{~h}$. Immunofluorescence image (overlay) of Ocl nuclei stained with Hoechst No. 33342 (Blue) together with FITC-phalloidin (Green) to visualize nuclei and the actin cytoskeleton. Using corresponding phase-contrast images, cell outlines were traced (Red) and superimposed for selected Ocl showing advanced induction of apoptosis. Bar is $100 \mu \mathrm{M}$. (c) Caspase-9 and 3 activities were measured in cell lysates after $20 \mathrm{~h}$ treatment of Ocl with increasing concentrations of rapamycin, as indicated. Data are mean \pm S.D. $(n=3)$. (d) MST1 kinase activities in Ocl lysates were measured by in-gel kinase assay. The relative activity (versus control) of the $36 \mathrm{kDa}$ caspase cleavage product of MST1 kinase is indicated beneath each lane

$(30 \mathrm{nM})$ reduced the generation of mature TRAP-positive Ocl in cocultures of murine bone marrow cells and MB1.8 osteoblast-like cells by $75 \%$ (Figure $6 \mathrm{a}$ ). This could be caused by suppression of the differentiation process or by the induction of Ocl apoptosis.

We examined induction of apoptosis using purified Ocls. Differentiated TRAP-positive Ocls generated in the coculture system were purified and maintained in the presence of $\mathrm{M}$ CSF and SRANKL with increasing concentrations of rapamycin. Rapamycin selectively suppresses the translation of polypyrimidine mRNAs, which encode elongation factors (eEF1 $\alpha$ and eEF2) and ribosomal proteins. However, its overall effect on protein translation is more gradual, with an approximate $40 \%$ reduction in translation observed $21-24 \mathrm{~h}$ after onset of treatment. ${ }^{48,49}$ In this study, there was no evidence of Ocl apoptosis at early time points; however, at 16-24 $\mathrm{h}$ rapamycin induced morphological features of apoptosis, including a loss of actin ring structure and membrane integrity as well as the formation of pyknotic nuclei (Figure 6b). Consistent with a slower rate of translation suppression by rapamycin, a subset of Ocl still remained intact for up to $24 \mathrm{~h}$. Thus, Ocl survival maintained by M-CSF and SRANKL could be blocked by the suppression of signaling through mTOR.

Rapamycin-induced apoptosis was further characterized by measuring caspase activities in cell lysates from treated and untreated Ocls (at $16 \mathrm{~h}$ ). Most consistently, maximal effects were observed with rapamycin at $10 \mathrm{nM}$ or above, whereby a six-fold induction in caspase-3 activity was seen both in individual experiments (Figure $6 \mathrm{c}$ ) and in averages across several independent experiments (6.9-fold, data not shown). A concentration of $1 \mathrm{nM}$ could induce caspase 3- up to fivefold (Figure 6c) with an average 4.1-fold induction seen across several independent experiments. Induction of caspase-9 was consistent with that of caspase- 3 in all experiments. In separate analyses, the proapoptotic $36 \mathrm{kDa}$ MST1 kinase was activated five-fold at 10 and $30 \mathrm{nM}$ (Figure 6d). The lower 
overall induction of caspase and $36 \mathrm{kDa}$ MST1 activity by rapamycin compared to $\mathrm{CHX}$ treatment reflects the more asynchronous versus synchronous induction of apoptosis, respectively. These findings indicate that mTOR activity contributes to Ocl survival, and inhibition of its activity results in increased Ocl apoptosis.

Since rapamycin can shorten the lifespan of Ocl by inducing apoptosis, we examined if it inhibits bone resorption as a functional consequence of this effect. Rabbit bone marrow cells were grown and differentiated on bovine cortical bone slices for 3-4 days in the absence or presence of increasing concentrations of rapamycin $(1-100 \mathrm{nM})$, which was added $4 \mathrm{~h}$ after seeding of marrow cells onto the bone slices. Rabbit Ocl bone resorption was measured by the release of collagenI degradation product (C-terminal telopeptides, CTX) into the culture supernatants (Figure 7). Time-course analyses revealed that little bone resorption takes place during the first $24 \mathrm{~h}$ of culture and that ALN effects are not seen until $48 \mathrm{~h}$ or more. ${ }^{50}$ We therefore examined rapamycin effects at 72 and $96 \mathrm{~h}$, where it was observed to reduce bone resorption significantly at all tested concentrations. During the first $72 \mathrm{~h}$, dose-dependent inhibition of up to $60 \%$ was observed,
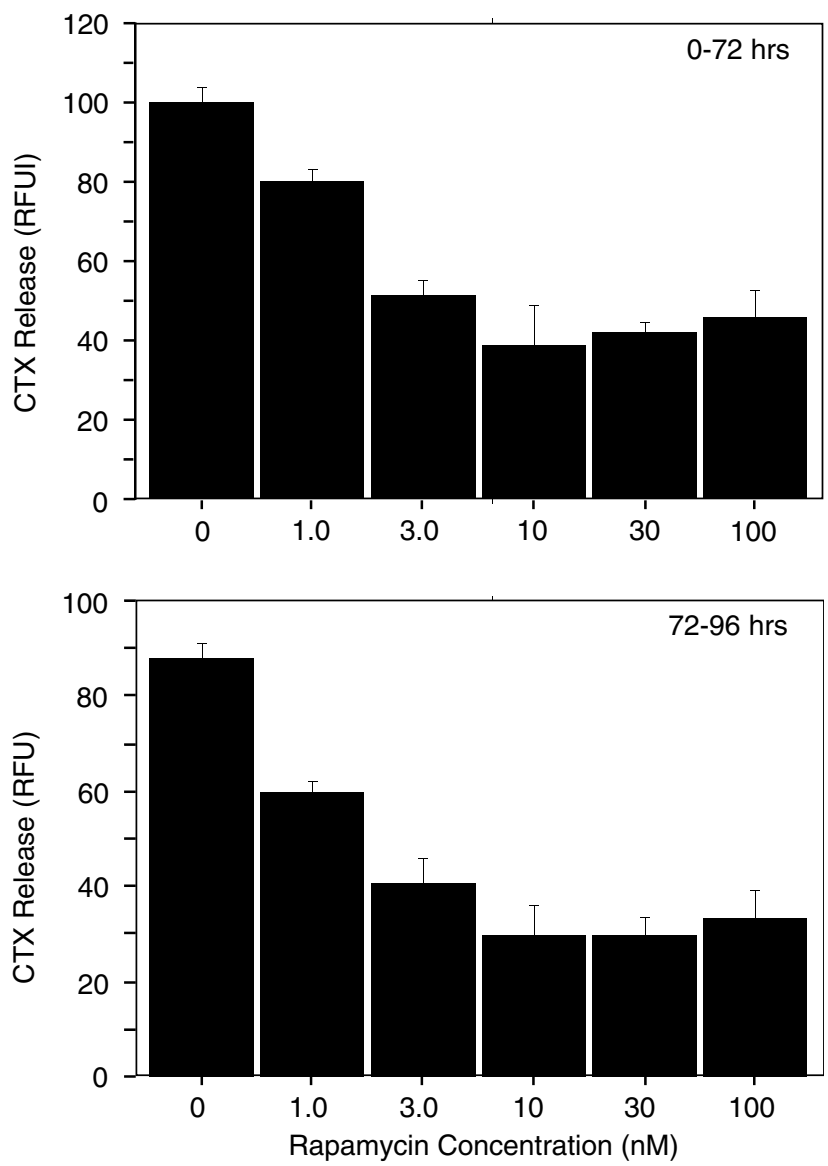

Figure 7 Inhibition of bone resorption by rapamycin. Rabbit bone marrow cells were seeded on bovine bone slices in 96-well plates and cultured in the absence or presence of rapamycin, at indicated concentrations, as described in Materials and Methods. Release of collagen-I C-terminal telopeptides (CTX) into the culture medium was measured after $72 \mathrm{~h}$ (upper panel) and between 72 and $96 \mathrm{~h}$ (lower panel). Data are mean \pm S.D. $(n=3)$ with an $\mathrm{IC}_{50}$ of $1-3 \mathrm{nM}$. During the next $24 \mathrm{~h}(72-96 \mathrm{~h}$ time period), resorption was suppressed by about $70 \%$. Similar dose dependence of apoptotic (Figure 6) and bone resorption effects (Figure 7) was observed in the respective mouse and rabbit models, with some slight variance at the lower end of the dosing range. As hypothesized, bone resorptive activity of rabbit $\mathrm{Ocl}$ at various concentrations of rapamycin correlated with the number of well-spread TRAP-positive cells on the bone slices $\left(r^{2}=0.94, P<0.0001\right)$. Similar reductions in rabbit Ocl number were seen when cells were cultured on plastic instead of bone, comparable to the results from mouse $\mathrm{Ocl}$ cocultures described above.

\section{Discussion}

A delicate balance between bone resorption by $\mathrm{Ocl}$ and deposition of new bone by osteoblasts determines bone mass in the adult undergoing consistent adaptive bone remodeling. Imbalance of these coupled activities in favor of bone resorption results in bone loss and deterioration of its trabecular architecture leading to osteoporosis. Regulation of Ocl survival was suggested as a means to regulate resorptive activities. ${ }^{13,14,51}$ Interestingly, cytokines produced by osteoblasts or stromal cells not only trigger differentiation, but also promote survival of mature Ocl. In this study, we describe for the first time an intersection of the signaling pathways induced in the Ocl by the antiapoptotic agents MCSF, TNF $\alpha$ and RANKL at the level of mTOR/S6K activation. We also show that Ocl's have an acute requirement for ongoing protein translation for survival. $\mathrm{mTOR} / \mathrm{S} 6 \mathrm{~K}$ regulation of protein translation may therefore play a critical role in regulating the lifespan of the Ocl, its bone-resorbing activity and, thus, play a role in regulating bone turnover.

The target of rapamycin, mTOR, is a Ser/Thr protein kinase and functions to regulate initiation and elongation phases of translation, as well as amino-acid import and the transcription of enzymes involved in multiple metabolic pathways. ${ }^{48,49,52}$ mTOR can play both pro- and antiapoptotic roles, although the mechanisms remain largely elusive (see Castedo et al. ${ }^{27}$ and references therein). In the present study, we demonstrate that mTOR is involved in the promotion of Ocl formation, survival and bone resorption. Interestingly, while suppressing apoptosis in multinucleated $\mathrm{Ocl}$ it also promotes apoptosis in HIVenv-fused cells. The latter response is linked to karyogamy, resulting in nuclear translocation of $\mathrm{mTOR}$ and subsequent p53 phosphorylation. ${ }^{53}$ Here, we show that rapamycin treatment induces apoptosis in Ocl in vitro, as measured by morphological changes, by increased caspase activities and by cleavage and activation of the proapoptotic MST1 kinase. Further, inhibition of mTOR activation resulted in fewer TRAPpositive Ocls and a significant reduction in bone resorption in vitro. This defines mTOR, as a critical factor required for downstream effects of M-CSF, RANKL and TNF $\alpha$ on the Ocl.

Cytokine control of protein translation including mTOR activation does not seem to function within a linear signaling pathway, since PI3K activity is also necessary for further downstream signaling (Figure 8). A working model has been proposed, where the absence of either signal would prohibit activation of downstream targets. ${ }^{52}$ In the Ocl, M-CSF was 


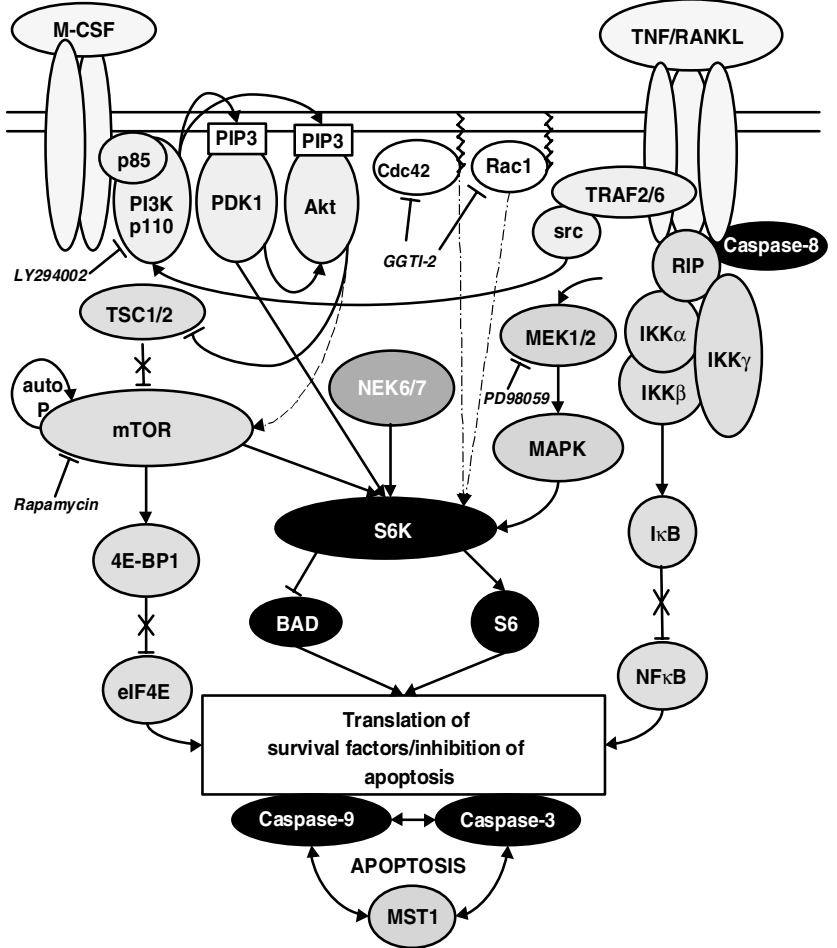

Figure 8 Schematic illustration of mTOR/S6K intracellular signal transduction pathways in the Ocl. M-CSF, TNF $\alpha$ and RANKL induced signaling leading to activation of translation and inhibition of apoptosis. For simplicity, TNF $\alpha$ receptor and RANK are shown as one receptor

shown to signal through the PI3K pathway to activate the prosurvival kinase, Akt (see Nakamura et al. ${ }^{19}$ and the present study). Signaling in Ocl to Akt by RANKL and TNF $\alpha$, via p60 ${ }^{\mathrm{c} \text {-src }}$ has also been reported. ${ }^{18,23}$ However, although we found robust Akt activation by M-CSF in the Ocl, we did not observe substantial crossover signaling from either TNF $\alpha$ or RANKL. To this extent, the observation that all three cytokines converge on mTOR, as observed here in the Ocl, is unique. Only very recently has a link been found between Akt and S6K via TSC2 (tuberin) and mTOR. ${ }^{28-30}$ Akt phosphorylation of TSC2, a negative regulator of $\mathrm{mTOR}$, derepresses the mTOR-inhibitory function of the TSC1/2 complex and results in phosphorylation of both S6K and 4E-BP1. This is consistent with the negative effects of PI3K, Akt and Src-family inhibitors on S6K activity stimulated by M-CSF, sRANKL and TNF $\alpha$ seen here and previously for PI3K- and Src-family inhibitors in insulin-stimulated S6K activation in myoblasts and fibroblasts. ${ }^{46}$ One discrepancy lies in the ability of SRANKL and $\mathrm{TNF} \alpha$ to induce S6 phosphorylation in the Ocl without augmenting Akt activity. However, it is notable that measurable baseline Akt phosphorylation was detected at all time points. Indeed, all three cytokines stimulated phosphorylation of S6, with similar kinetics, with M-CSF-induced Akt activation rising and substantially declining prior to induction of S6K activity. This suggests that only a modest level of Akt activity is necessary and sufficient for S6K activation. As such, the TSC1/2 inhibition of mTOR may already be sufficiently derepressed in the Ocl, thus requiring only positive stimuli for S6K activation.
In addition to mTOR, S6K can be considered to be an integrator of diverse intracellular signal transduction pathways in the Ocl (Figure 8). Cytokine-mediated activation of S6K is a multistep process involving mTOR, NEK6 and PDK1. These kinases and mTOR-mediated suppression of a rapamycinsensitive phosphatase have all been implicated in the phosphorylation of Thr389, a critical residue within the S6K autoinhibitory domain. ${ }^{31-34}$ Phosphorylation of S6K at Thr389 releases the kinase from autoinhibition, enabling activation by PDK1 through phosphorylation of S6K (Thr229) within the kinase domain. We therefore used a phosphorylation statespecific antibody directed to Thr389 to assess cytokine activation in the Ocl. We found that M-CSF, TNF $\alpha$ and sRANKL all induce S6K phosphorylation in $\mathrm{Ocl}$ in a rapamycin-sensitive manner.

Erks also play a role in modulating S6K activity by targeting Thr421 and Thr424 in the $\mathrm{COOH}$-terminal region. Previous work has shown that Erk1 and -2 are activated in Ocl by cytokine treatments, and Erk activation prevents Ocl apoptosis. ${ }^{18,23,54}$ Consistent with this, we detected cytokine-induced phosphorylation of S6K at Thr421 and Thr424 using phosphorylation state-specific antibodies (data not shown). Furthermore, suppression of Erk activation with the Mek inhibitor, PD98059, resulted in partial suppression of S6K activity, as measured by $\mathrm{S} 6$ phosphorylation.

Other pathways upstream of S6K include geranylgeranylated small GTPases, such as Cdc42 and Rac1. ${ }^{47}$ This seems important since M-CSF, TNF $\alpha$ and SRANKL, which activate S6K, also suppress induction of ALN- and GGTI-2-induced apoptosis at relatively high concentrations. This, together with the observation that GGTI-2 substantially reduces signaling of these cytokines through S6K, suggests a possible convergence of pro- and antiapoptotic signals of these agents in the Ocl. By inference, ALN and other nitrogen-containing bisphosphonates, which act in the Ocl via suppression of geranylgeranylation, ${ }^{16,39,40,55}$ may induce apoptosis and suppress osteoclastic bone resorption, in part, via suppressing the mTOR/S6K pathway. This is also supported by the observation that rapamycin treatment induces apoptosis in Ocl with similar kinetics.

The antiapoptotic effect of mTOR identifies this enzyme as an essential participant in cytokine-induced prosurvival signal transduction in $\mathrm{Ocl}$, in addition to Akt and NF- $\kappa \mathrm{B}$, probably acting via its positive impact on protein translation. Possible pathways for mTOR-dependent suppression of apoptosis in the Ocl include S6K-mediated phosphorylation and thus inactivation of the proapoptotic BCL-2 family member, BAD. ${ }^{35}$ However, in Ocl, lysates we were unable to detect BAD protein and phosphorylation thereof, possibly due to very low levels of expression (data not shown).

A possible mechanism for rapamycin induction of $\mathrm{Ocl}$ apoptosis is via its suppressive effects on mTOR, S6K and, ultimately, 4E-BP1 and S6. Rapamycin inhibition of translation could lead to inadequate synthesis of a set of proteins that include survival factor(s), which according to their normal rate of turnover, become rate limiting. In this context, $\mathrm{Li}$ et al. ${ }^{56}$ found a role for 4E-BP1 in the translational control of proteins critical for cell survival. We observed in this study the suppressed phosphorylation of 4E-BP1 by treatment of Ocl with rapamycin, which may account for part of the apoptotic 
response. Expression of BCL-2-like proteins, such as MCL-1, can be attenuated by rapamycin. ${ }^{57}$ Very recently Woltman et al. $^{58}$ reported that GM-CSF-mediated survival of dendritic cells indeed depends on PI3K/mTOR signaling and MCL-1. These findings along with those presented here suggest a broader involvement of mTOR in cell survival within the monocyte/macrophage-derived cell lineages. We therefore postulate that such proteins may play a critical role in the Ocl and in the responses described here. ${ }^{59}$ Taken together, we can conclude that tight control of translation seems to be necessary to provide BCL-2-like proteins and prolong $\mathrm{Ocl}$ survival. ${ }^{60,61}$ Identification of responsible candidate proteins is the subject of further research.

In summary, we describe for the first time a shared role for mTOR/S6K in the prosurvival signaling of osteoclastogenic cytokines. Inhibition of this translational control pathway results in initiation of apoptosis in Ocl in vitro and ultimately reduces bone resorption. The Ocl exhibits an acute dependence on continual protein translation for survival, a property not commonly found in most cells. This study therefore suggests downstream effectors of mTOR and S6K, including 4E-BP1, S6 and, possibly, BCL-2 family proteins to contribute to the survival of these bone-resorbing cells.

\section{Materials and Methods}

\section{Cell culture and reagents}

Ocl-like cells were generated by coculturing mouse bone marrow cells (from two mice) together with mouse MB1.8 cells in differentiation medium (MEM- $\alpha$ supplemented with $10 \%$ FBS and $10 \mathrm{nM} 1.25(\mathrm{OH})_{2}-$ Vitamin $\mathrm{D}_{3}$ ) in six-well plates maintained in a humidified atmosphere with $10 \% \mathrm{CO}_{2}{ }^{62}$ MB1.8 cells were removed by collagenase treatment ${ }^{63}$ and purified $\mathrm{Ocl}$ were further cultured in the presence of $10-15 \mathrm{ng} / \mathrm{ml} \mathrm{M-CSF}$ (R\&D, Minneapolis, MN, USA) to suppress spontaneous apoptosis. For signal transduction experiments Ocl were cultured in $0.5 \%$ FBS without M-CSF for 1-2 $\mathrm{h}$. Ocl were then treated either with M-CSF (40 ng/ml; R\&D), TNF $\alpha$ (50 ng/ml; R\&D), IL-1 $\alpha$ (50 ng/ml; R\&D) or sRANKL (100 ng/ml; R\&D) for various times in $0.5 \% \mathrm{FBS}$. The following reagents were used at indicated concentrations: cycloheximide ( $50 \mu \mathrm{M}$; Biovision Inc., Mountain View, CA, USA), puromycin (50 $\mu \mathrm{g} / \mathrm{ml}$, Sigma; St. Louis, MO, USA), emetine (50 $\mu \mathrm{g} /$ $\mathrm{ml}$, Sigma), actinomycin D $(5 \mu \mathrm{M}$; Biovision), rapamycin $(3-100 \mathrm{nM}$, Calbiochem, San Diego, CA, USA), LY 294002 (5 $\mu \mathrm{M}$, Calbiochem), Akt inhibitor (10 $\mu \mathrm{M}$; Calbiochem), PD98059 (20 $\mu \mathrm{M}$; Alexis Corp., San Diego, CA, USA). GGTI-2 was a kind gift of Bill Lumma (Department of Medicinal Chemistry, Merck \& Co., Inc.).

\section{Preparation of protein lysates and Western blotting}

After treatments, cells were placed on ice and washed twice with ice-cold $\beta$-glycerophosphate-HEPES-buffered solution ( $\beta$-HBS): $50 \mathrm{mM}$ HEPES (pH 7.6), $\beta$-glycerophosphate $(50 \mathrm{mM})$, EGTA $(1 \mathrm{mM}), \mathrm{NaCl}(150 \mathrm{mM})$, and then lysed in $\beta$-HBS containing Triton X-100 (0.2\%), microcystin LR $(1 \mu \mathrm{M}), \mathrm{Na}_{3} \mathrm{VO}_{4}(1 \mathrm{mM})$, dithiothreitol $(1 \mathrm{mM})$, and phenylmethylsulfonyl fluoride (1 mM) and a protease inhibitor mixture (Sigma) as described. ${ }^{16,40}$ Protein concentrations were determined using a Bradford reagent kit (BioRad, Hercules, CA, USA). Typically, $10-15 \mu \mathrm{g}$ of protein lysate could be generated from one well.

Equal amounts of protein lysates were loaded and separated on 12 or $4-15 \%$ gradient Tris- $\mathrm{HCl}$ gels (Bio-Rad). Proteins were transferred on
PVDF membranes, which were blocked with $5 \%$ nonfat milk $/ 5 \%$ BSA in TBST (10 mM Tris- $\mathrm{HCl} \mathrm{pH} 8.0,150 \mathrm{mM} \mathrm{NaCl}, 0.1 \%$ Tween-20). Primary antibodies were incubated overnight at $4{ }^{\circ} \mathrm{C}$ with gentle agitation. Antiphospho-p70 S6 Kinase (Thr389) antibody, anti-p70 S6 kinase antibody, phospho-S6 ribosomal protein (Ser235/236) antibody, phospho4E-BP1 (Ser65) antibody, phospho-Akt (Ser473), phospho-Akt (Thr 308), anti-Akt antibody, phospho- $\mid \kappa \mathrm{B} \alpha(\mathrm{Ser} 32 / 36)$ antibody (all from Cell Signaling Technology, Beverly, MA, USA), and anti- $\kappa_{\kappa} \mathrm{B} \alpha$ antibody (Santa Cruz Biotechnology Inc., Santa Cruz, CA, USA) were diluted 1:1000 in blocking solution. Detection was performed with alkaline phosphatase coupled secondary antibodies (1:10,000, Santa Cruz) and ECF substrate (Amersham, Piscataway, NJ, USA) using a Molecular Dynamics Storm 860 system (Sunnyvale, CA, USA).

\section{In-gel kinase assay}

Kinase assays were performed in the gel using myelin basic protein (MBP) as a substrate, essentially as described with one modification: kinase buffer contained $20 \mathrm{mM} \mathrm{MgCl}_{2}$ in place of $5 \mathrm{mM} \mathrm{MnCl}_{2}{ }^{16}$ Lanes were loaded with equivalent amounts of protein lysate (5-10 $\mu \mathrm{g} / \mathrm{lane})$, and then gels were electrophoresed and processed for kinase assay. Dried gels were exposed to phosphorimaging screens and scanned and analyzed using the Storm 860 system.

\section{NF- $\kappa$ B activity assay}

Ocl in six-well plates were incubated in regular growth medium supplemented with $10 \mathrm{ng} / \mathrm{ml}$ M-CSF overnight. Cells were starved in growth medium $+0.5 \%$ FBS without M-CSF for $1 \mathrm{~h}$ and then TNF $\alpha(50 \mathrm{ng} /$ $\mathrm{ml})$, RANKL $(100 \mathrm{ng} / \mathrm{ml})$ or M-CSF $(80 \mathrm{ng} / \mathrm{ml})$ was added for the times indicated. Whole-cell lysates were prepared and samples from three separate identically treated wells were pooled. This was necessary to generate sufficient material for assay. Using pooled samples, activated p65 NF- $\kappa$ B (RelA) was measured using a Trans-AM NF- $\kappa$ B Transcription Factor Assay Kit (Active Motif, Carlsbad, CA, USA) according to the manufacturer's instructions. For this assay, activity is measured in a 96well format assessing both NF- $\kappa$ B-DNA binding and, simultaneously, antibody binding to a NF- $\kappa \mathrm{B}$ epitope that is inaccessible when in a complex with $\mathrm{l}_{\kappa} \mathrm{B}$.

\section{Caspase activity assay}

The fluorescent caspase-3 activity assay kit was from Biovision Inc.; the caspase-9 activity assay kit was from Oncogene Research Products (Boston, MA, USA). Cells were washed with Hank's-buffered salt solution (HBSS), and lysed and scraped in the lysis buffer supplied by the manufacturer. As with assays for NF- $\kappa$ B activation, lysates from two to three independently treated wells were pooled to generate sufficient material for assay. Lysates were cleared by centrifugation and supernatants were assayed according to instructions provided with each kit. Total protein $(20-40 \mu \mathrm{g})$ was used per assay, and activities were determined after $2 \mathrm{~h}$ incubation at $37^{\circ} \mathrm{C}$. Values are in relative fluorescence units (RFUs) $/ \mu \mathrm{g}$ protein.

\section{Fluorescent TRAP-activity assay}

Cocultures of bone marrow cells and MB1.8 cells in 24-well plates were treated with $30 \mathrm{nM}$ rapamycin for 7 days. Cells were washed with HBSS and lysed in $250 \mu$ l solution ( $50 \mathrm{mM}$ sodium acetate $(\mathrm{pH} 5.0), 30 \mathrm{mM}$ sodium tartrate, $0.1 \%$ Triton X-100, $2.5 \mathrm{mg} / \mathrm{ml}$ naphthol AS-BI phosphate) for $30 \mathrm{~min}$ at $37^{\circ} \mathrm{C}$. Reactions were stopped by adding $12.5 \mu \mathrm{l} 1 \mathrm{M} \mathrm{NaOH}$ 
and TRAP activity was measured with a fluorescent plate reader (ex.360 nm/em.530 nm).

\section{Histochemistry}

Ocl-like cells were washed with HBSS and fixed in 3.7\% formaldehyde for $15 \mathrm{~min}$ and stained essentially as described. ${ }^{50}$ Briefly, cells were stained for TRAP in $50 \mathrm{mM}$ sodium acetate ( $\mathrm{pH} 5.0$ ), $30 \mathrm{mM}$ sodium tartrate, $0.1 \%$ Triton X-100 with $0.3 \mathrm{mg} / \mathrm{ml}$ fast red violet LB (Sigma, St. Louis, MO, USA) and $0.1 \mathrm{mg} / \mathrm{ml}$ naphthol AS-MX phosphate (Sigma). Actin and nuclei were stained with $5 \mathrm{U} / \mathrm{ml}$ TRITC or FITC-labeled phalloidin (Molecular Probes, Eugene, OR, USA) together with $50 \mu \mathrm{g} / \mathrm{ml}$ Hoechst 33342 dye (Molecular Probes).

\section{Bone resorption assay}

Bone resorption by Ocl's differentiated from New Zealand White rabbit tibiae (Covance Research Products, Denver, PA, USA) was measured as described. ${ }^{63}$ Briefly, tibiae were minced and bone fragments rocked gently in $\alpha$-MEM with $10 \mathrm{mM} \mathrm{HEPES} \mathrm{(pH} \mathrm{7.1).} \mathrm{A} \mathrm{total} \mathrm{of} 10^{6}$ cells/well in $\alpha$-MEM supplemented with $10 \% \mathrm{FBS}$ and $10 \mathrm{nM} 1.25(\mathrm{OH})_{2}-$ Vitamin $\mathrm{D}_{3}$ were seeded on bovine bone slices in 96-well plates and cultured for $4 \mathrm{~h}$. Thereafter, rapamycin (3-100 nM) was added in triplicate and cultures were continued for additional 68 or $92 \mathrm{~h}$ (72 or $96 \mathrm{~h}$ total in culture). Collagen fragments released into the medium were measured by the CrossLaps ELISA assay (Osteometer Biotech, Herlev, Denmark). Statistical analysis was performed with StatView (SAS Institute Inc., Cary, NC, USA).

\section{Acknowledgements}

We thank William Lumma (Department of Medicinal Chemistry, Merck Research Laboratories) for the generous gift of GGTI-2; and Hans Huber and Debbie Defeo-Jones (Department of Cancer Research, Merck Research Laboratories) for helpful discussions.

\section{References}

1. Teitelbaum SL (2000) Bone resorption by osteoclasts. Science 289: 15041508

2. Rodan GA and Martin TJ (2000) Therapeutic approaches to bone diseases. Science 289: 1508-1514

3. Duong LT and Rodan GA (2001) Regulation of osteoclast formation and function. Rev. Endocr. Metab. Disord. 2: 95-104

4. Felix R, Cecchini MG, Hofstetter W, Elford PR, Stutzer A and Fleisch H (1990) Impairment of macrophage colony-stimulating factor production and lack of resident bone marrow macrophages in the osteopetrotic op/op mouse. J. Bone Miner. Res. 5: 781-789

5. Kodama H, Yamasaki A, Nose M, Niida S, Ohgame Y, Abe M, Kumegawa M and Suda T (1991) Congenital osteoclast deficiency in osteopetrotic (op/op) mice is cured by injections of macrophage colony-stimulating factor. J. Exp. Med. 173: 269-272

6. Dai XM, Ryan GR, Hapel AJ, Dominguez MG, Russell RG, Kapp S, Sylvestre V and Stanley ER (2002) Targeted disruption of the mouse colony-stimulating factor 1 receptor gene results in osteopetrosis, mononuclear phagocyte deficiency, increased primitive progenitor cell frequencies, and reproductive defects. Blood 99: 111-120

7. Anderson DM, Maraskovsky E, Billingsley WL, Dougall WC, Tometsko ME, Roux ER, Teepe MC, DuBose RF, Cosman D and Galibert L (1997) A homologue of the TNF receptor and its ligand enhance T-cell growth and dendritic-cell function. Nature 390: 175-179
8. Lacey DL, Timms E, Tan HL, Kelley MJ, Dunstan CR, Burgess T, Elliott R, Colombero A, Elliott G, Scully S, Hsu H, Sullivan J, Hawkins N, Davy E, Capparelli C, Eli A, Qian YX, Kaufman S, Sarosi I, Shalhoub V, Senaldi G, Guo J, Delaney J and Boyle WJ (1998) Osteoprotegerin ligand is a cytokine that regulates osteoclast differentiation and activation. Cell 93: 165-176

9. Yasuda H, Shima N, Nakagawa N, Yamaguchi K, Kinosaki M, Mochizuki S, Tomoyasu A, Yano K, Goto M, Murakami A, Tsuda E, Morinaga T, Higashio K, Udagawa N, Takahashi N and Suda T (1998) Osteoclast differentiation factor is a ligand for osteoprotegerin/osteoclastogenesis-inhibitory factor and is identical to TRANCE/RANKL. Proc. Natl. Acad. Sci. USA 95: 3597-3602

10. Kobayashi K, Takahashi N, Jimi E, Udagawa N, Takami M, Kotake S, Nakagawa N, Kinosaki M, Yamaguchi K, Shima N, Yasuda H, Morinaga T, Higashio K, Martin TJ and Suda T (2000) Tumor necrosis factor alpha stimulates osteoclast differentiation by a mechanism independent of the ODF/ RANKL-RANK interaction. J. Exp. Med. 191: 275-286

11. Lam J, Takeshita S, Barker JE, Kanagawa O, Ross FP and Teitelbaum SL (2000) TNF-alpha induces osteoclastogenesis by direct stimulation of macrophages exposed to permissive levels of RANK ligand. J. Clin. Invest. 106: $1481-1488$

12. Fuller K, Murphy C, Kirstein B, Fox SW and Chambers TJ (2002) TNFalpha potently activates osteoclasts, through a direct action independent of and strongly synergistic with RANKL. Endocrinology 143: 1108-1118

13. Parfitt AM, Mundy GR, Roodman GD, Hughes DE and Boyce BF (1996) A new model for the regulation of bone resorption, with particular reference to the effects of bisphosphonates. J. Bone Miner. Res. 11: 150-159

14. Manolagas SC (2000) Birth and death of bone cells: basic regulatory mechanisms and implications for the pathogenesis and treatment of osteoporosis. Endocr. Rev. 21: 115-137

15. Fuller K, Owens JM, Jagger CJ, Wilson A, Moss R and Chambers TJ (1993) Macrophage colony-stimulating factor stimulates survival and chemotactic behavior in isolated osteoclasts. J. Exp. Med. 178: 1733-1744

16. Reszka AA, Halasy-Nagy JM, Masarachia PJ and Rodan GA (1999) Bisphosphonates act directly on the osteoclast to induce caspase cleavage of MST1 kinase during apoptosis. A link between inhibition of the mevalonate pathway and regulation of an apoptosis-promoting kinase. J. Biol. Chem. 274: 34967-34973

17. Lacey DL, Tan HL, Lu J, Kaufman S, Van G, Quu W, Rattan A, Scully S, Fletcher F, Juan T, Kelley M, Burgess TL, Boyle WJ and Polverino AJ (2000) Osteoprotegerin ligand modulates murine osteoclast survival in vitro and in vivo. Am. J. Pathol. 157: 435-448

18. Lee SE, Chung WJ, Kwak HB, Chung CH, Kwack KB, Lee ZH and Kim HH (2001) Tumor necrosis factor-alpha supports the survival of osteoclasts through the activation of Akt and ERK. J. Biol. Chem. 276: 49343-49349

19. Nakamura I, Lipfert L, Rodan GA and Duong LT (2001) Convergence of alpha(v)beta(3) integrin- and macrophage colony stimulating factor-mediated signals on phospholipase Cgamma in prefusion osteoclasts. J. Cell Biol. 152: 361-373

20. Datta SR, Brunet A and Greenberg ME (1999) Cellular survival: a play in three Akts. Genes Dev. 13: 2905-2927

21. Kelley TW, Graham MM, Doseff Al, Pomerantz RW, Lau SM, Ostrowski MC, Franke TF and Marsh CB (1999) Macrophage colony-stimulating factor promotes cell survival through Akt/protein kinase B. J. Biol. Chem. 274: 2639326398

22. Barkett M and Gilmore TD (1999) Control of apoptosis by Rel/NF-kappaB transcription factors. Oncogene 18: 6910-6924

23. Wong BR, Besser D, Kim N, Arron JR, Vologodskaia M, Hanafusa $\mathrm{H}$ and Choi $Y$ (1999) TRANCE, a TNF family member, activates Akt/PKB through a signaling complex involving TRAF6 and c-Src. Mol. Cell. 4: 1041-1049

24. Xing L, Venegas AM, Chen A, Garrett-Beal L, Boyce BF, Varmus HE and Schwartzberg PL (2001) Genetic evidence for a role for Src family kinases in TNF family receptor signaling and cell survival. Genes Dev. 15: 241-253

25. Ozes ON, Mayo LD, Gustin JA, Pfeffer SR, Pfeffer LM and Donner DB (1999) NF-kappaB activation by tumour necrosis factor requires the Akt serinethreonine kinase. Nature 401: 82-85

26. Delhase M, Li N and Karin M (2000) Kinase regulation in inflammatory response. Nature 406: 367-368

27. Castedo M, Ferri KF and Kroemer G (2002) Mammalian target of rapamycin (mTOR): pro- and anti-apoptotic. Cell Death Differ. 9: 99-100 
28. Inoki K, Li Y, Zhu T, Wu J and Guan KL (2002) TSC2 is phosphorylated and inhibited by Akt and suppresses mTOR signalling. Nat. Cell Biol. 4: 648-657

29. Potter CJ, Pedraza LG and Xu T (2002) Akt regulates growth by directly phosphorylating Tsc2. Nat. Cell Biol. 4: 658-665

30. Tee AR, Fingar DC, Manning BD, Kwiatkowski DJ, Cantley LC and Blenis J (2002) Tuberous sclerosis complex-1 and -2 gene products function together to inhibit mammalian target of rapamycin (mTOR)-mediated downstream signaling. Proc. Natl. Acad. Sci. USA 99: 13571-13576

31. Alessi DR, Kozlowski MT, Weng QP, Morrice N and Avruch J (1998) 3Phosphoinositide-dependent protein kinase 1 (PDK1) phosphorylates and activates the p70 S6 kinase in vivo and in vitro. Curr. Biol. 8: 69-81

32. Burnett PE, Barrow RK, Cohen NA, Snyder SH and Sabatini DM (1998) RAFT1 phosphorylation of the translational regulators p70 S6 kinase and 4E-BP1. Proc. Natl. Acad. Sci. USA 95: 1432-1437

33. Belham C, Comb MJ and Avruch J (2001) Identification of the NIMA family kinases NEK6/7 as regulators of the p70 ribosomal $\mathrm{S} 6$ kinase. Curr. Biol. 11: $1155-1167$

34. Dufner A and Thomas G (1999) Ribosomal S6 kinase signaling and the control of translation. Exp. Cell Res. 253: 100-109

35. Harada H, Andersen JS, Mann M, Terada N and Korsmeyer SJ (2001) p70S6 kinase signals cell survival as well as growth, inactivating the pro-apoptotic molecule BAD. Proc. Natl. Acad. Sci. USA 98: 9666-9670

36. Graves JD, Draves KE, Gotoh Y, Krebs EG and Clark EA (2001) Both phosphorylation and caspase-mediated cleavage contribute to regulation of the Ste20-like protein kinase MST1 during CD95/Fas-induced apoptosis. J. Biol. Chem. 276: 14909-14915

37. Ura S, Masuyama N, Graves JD and Gotoh Y (2001) Caspase cleavage of MST1 promotes nuclear translocation and chromatin condensation. Proc. Natl. Acad. Sci. USA 98: 10148-10153

38. Glantschnig H, Rodan GA and Reszka AA (2002) Mapping of MST1 kinase sites of phosphorylation. Activation and autophosphorylation. J. Biol. Chem. 277: 42987-42996

39. Coxon FP, Helfrich MH, Van't Hof R, Sebti S, Ralston SH, Hamilton and Rogers MJ (2000) Protein geranylgeranylation is required for osteoclast formation, function, and survival: inhibition by bisphosphonates and GGTI-298. J. Bone Miner. Res. 15: 1467-1476

40. Reszka AA, Halasy-Nagy J and Rodan GA (2001) Nitrogen-bisphosphonates block retinoblastoma phosphorylation and cell growth by inhibiting the cholesterol biosynthetic pathway in a keratinocyte model for esophageal irritation. Mol. Pharmacol. 59: 193-202

41. Lobell RB, Omer CA, Abrams MT, Bhimnathwala HG, Brucker MJ, Buser CA Davide JP, deSolms SJ, Dinsmore CJ, Ellis-Hutchings MS, Kral AM, Liu D, Lumma WC, Machotka SV, Rands E, Williams TM, Graham SL, Hartman GD, Oliff Al, Heimbrook DC and Kohl NE (2001) Evaluation of farnesyl: protein transferase and geranylgeranyl: protein transferase inhibitor combinations in preclinical models. Cancer Res. 61: 8758-8768

42. Polunovsky VA, Wendt CH, Ingbar DH, Peterson MS and Bitterman PB (1994) Induction of endothelial cell apoptosis by TNF alpha: modulation by inhibitors 0 protein synthesis. Exp. Cell Res. 214: 584-594

43. Sugiyama H, Savill JS, Kitamura M, Zhao L and Stylianou E (1999) Selective sensitization to tumor necrosis factor-alpha-induced apoptosis by blockade of NF-kappaB in primary glomerular mesangial cells. J. Biol. Chem. 274: 1953219537

44. Brunn GJ, Williams J, Sabers C, Wiederrecht G, Lawrence Jr JC and Abraham RT (1996) Direct inhibition of the signaling functions of the mammalian target of rapamycin by the phosphoinositide 3-kinase inhibitors, wortmannin and LY294002. EMBO J. 15: 5256-5267

45. Hu Y, Qiao L, Wang S, Rong SB, Meuillet EJ, Berggren M, Gallegos A, Powis G and Kozikowski AP (2000) 3-(Hydroxymethyl)-bearing phosphatidylinositol ether lipid analogues and carbonate surrogates block PI3-K, Akt, and cancer cell growth. J. Med. Chem. 43: 3045-3051

46. Shah OJ, Kimball SR and Jefferson LS (2002) The src-family tyrosine kinase inhibitor PP1 interferes with activation of ribosomal protein S6 kinases. Biochem. J. 366: 57-62
47. Chou MM and Blenis J (1996) The $70 \mathrm{kDa}$ S6 kinase complexes with and is activated by the Rho family G proteins Cdc42 and Rac1. Cell 85: 573-583

48. Jefferies HB, Reinhard C, Kozma SC and Thomas G (1994) Rapamycin selectively represses translation of the 'polypyrimidine tract' mRNA family. Proc. Natl. Acad. Sci. USA 91: 4441-4445

49. Terada N, Patel HR, Takase K, Kohno K, Nairn AC and Gelfand EW (1994) Rapamycin selectively inhibits translation of mRNAs encoding elongation factors and ribosomal proteins. Proc. Natl. Acad. Sci. USA 91: 11477-11481

50. Halasy-Nagy JM, Rodan GA and Reszka AA (2001) Inhibition of bone resorption by alendronate and risedronate does not require osteoclast apoptosis. Bone 29: 553-559

51. Rodan GA (1998) Control of bone formation and resorption: biological and clinical perspective. J. Cell. Biochem. Suppl. 30-31: 55-61

52. Raught B, Gingras AC and Sonenberg N (2001) The target of rapamycin (TOR) proteins. Proc. Natl. Acad. Sci. USA 98: 7037-7044

53. Castedo M, Roumier T, Blanco J, Ferri KF, Barretina J, Tintignac LA, Andreau $\mathrm{K}$, Perfettini JL, Amendola A, Nardacci R, Leduc P, Ingber DE, Druillennec, Roques B, Leibovitch SA, Vilella-Bach M, Chen J, Este JA, Modjtahedi N, Piacentini M and Kroemer G (2002) Sequential involvement of Cdk1, mTOR and p53 in apoptosis induced by the HIV-1 envelope. EMBO J. 21: 4070-4080

54. Miyazaki T, Katagiri $H$, Kanegae $Y$, Takayanagi $H$, Sawada $Y$, Yamamoto A, Pando MP, Asano T, Verma IM, Oda H, Nakamura K and Tanaka S (2000) Reciprocal role of ERK and NF-kappaB pathways in survival and activation of osteoclasts. J. Cell Biol. 148: 333-342

55. Van Beek ER, Lowik CW and Papapoulos SE (2002) Bisphosphonates suppress bone resorption by a direct effect on early osteoclast precursors without affecting the osteoclastogenic capacity of osteogenic cells: the role of protein geranylgeranylation in the action of nitrogen-containing bisphosphonates on osteoclast precursors. Bone 30: 64-70

56. Li S, Sonenberg N, Gingras AC, Peterson M, Avdulov S, Polunovsky VA and Bitterman PB (2002) Translational control of cell fate: availability of phosphorylation sites on translational repressor 4E-BP1 governs its proapoptotic potency. Mol. Cell. Biol. 22: 2853-2861

57. Schubert KM and Duronio V (2001) Distinct roles for extracellular-signalregulated protein kinase (ERK) mitogen-activated protein kinases and phosphatidylinositol 3-kinase in the regulation of Mcl-1 synthesis. Biochem. J. 356: $473-480$

58. Woltman AM, Van Der Kooij SW, Coffer PJ, Offringa R, Daha MR and Van Kooten C (2003) Rapamycin specifically interferes with GM-CSF signaling in human dendritic cells leading to apoptosis via increased p27KIP1 expression. Blood 101: 1439-1445

59. Glantschnig $H$ and Reszka AA (2002) Life is short, art long. Bcl-2 and osteoclast survival. IBMS BoneKEy Sep16 10.1138/ibmske;2002059

60. Hentunen TA, Reddy SV, Boyce BF, Devlin R, Park HR, Chung H, Selander KS, Dallas M, Kurihara N, Galson DL, Goldring SR, Koop BA, Windle JJ and Roodman GD (1998) Immortalization of osteoclast precursors by targeting Bcl$\mathrm{XL}$ and Simian virus 40 large $\mathrm{T}$ antigen to the osteoclast lineage in transgenic mice. J. Clin. Invest. 102: 88-97

61. McGill GG, Horstmann M, Widlund HR, Du J, Motyckova G, Nishimura EK, Lin YL, Ramaswamy S, Avery W, Ding HF, Jordan SA, Jackson IJ, Korsmeyer SJ, Golub TR and Fisher DE (2002) Bcl2 regulation by the melanocyte master regulator Mitf modulates lineage survival and melanoma cell viability. Cell 109: $707-718$

62. Wesolowski G, Duong LT, Lakkakorpi PT, Nagy RM, Tezuka K, Tanaka H, Rodan GA and Rodan SB (1995) Isolation and characterization of highly enriched, prefusion mouse osteoclastic cells. Exp. Cell Res. 219: 679-686

63. Fisher JE, Rogers MJ, Halasy JM, Luckman SP, Hughes DE, Masarachia PJ, Wesolowski G, Russell RG, Rodan GA and Reszka AA (1999) Alendronate mechanism of action: geranylgeraniol, an intermediate in the mevalonate pathway, prevents inhibition of osteoclast formation, bone resorption, and kinase activation in vitro. Proc. Natl. Acad. Sci. USA 96: 133-138 